\title{
Practicing Phenomenological Writing
}

\section{Max van Manen}

The University of Alberta

\section{Introduction}

This article on phenomenological research and writing has been used as a handout in a course entitled "Pedagogical Theorizing." In this course ${ }^{1}$ we address the questions: "What is phenomenology?" "How can phenomenological research contribute to pedagogic competence?" and "What is involved in phenomenological writing?" This handout is meant to aid with the third question.

The course itself involves an introductory reading of literature about phenomenology and literature exemplifying phenomenology. Some basic phenomenological terminology is introduced, and all through the course students are engaged in writing practices meant to orient them to bringing to speech their awareness of the meaning structures of lived experience, the world as we experience it in everyday life.

The end of phenomenological research is to sponsor a critical educational competence: knowing how to act tactfully in pedagogic situations on the basis of a carefully edified thoughtfulness. Phenomenological research does this by reintegrating part and whole, the contingent and the essential, value and desire. It sponsors a certain attentive awareness to the details and seemingly trivial dimensions of our everyday educational lives. It makes us thoughtfully aware of the consequential in the inconsequential, the significant in the taken-for-granted. This is evident, for example, in the topics which participants in the course Pedagogical Theorizing chose. ${ }^{2}$ Here are some of them: Naming Our Children; Re-reading a Book; Fear of Water; Working-out; Writing; Stepmothering; The Teacher's Look; The Child's Drawing; Show 'n Tell; Joy in Teaching; Giving an Injection; The Experience of Difficulty; Playing School; Birthing Pain; The Failing Grade; My School Desk; and so on. Each topic, without fail, figures significantly in the personal or professional life circumstances of the student researching it.

Marie Laing, who researched the topic "naming our children," had never as a child felt at peace with her own first name; divorced for fifteen years, she still carries the family name of her husband. In her professional life as educator and practicing psychologist she has been impressed with the power of names in the lives of children and adults. Similarly, Colin Lorback, who is a professor of physical education, has research interest in teaching swimming to "the abso- 
lutely scared," those with fear of water. Alan Shapiro is an elementary school teacher who feels that there is more to the ritualistic "show 'n tell" (while teacher does her planbook) than most elementary school teachers acknowledge. Peggy Ann Field is a professor of nursing who is intrigued with something all nurses she teaches had to face: the experience of giving an injection. Gerry Bourque is a forensic psychologist who has dealt for many years with genital exhibitionists and who has become uncomfortable with the prejudicial gloss both experts and lay people place over the experiential nature of this sexual and social deviancy. An art teacher, Donna Reimche, wonders whether we really know what drawing is like for children. Vangie Kelpin is a health educator, a pre-natal instructor who over the years has become uncomfortable with a certain question that often emerged with women who had given birth: why did you not tell me about the pain? The list goes on and each topic is indeed as interesting as it sounds or, in fact, even much more so. Quite a few students have used this writing as a starting point for a more fullfledged piece of phenomenological thesis research.

But most of the course papers, the phenomenological descriptions, are brief, hardly qualifying it would seem as the evaluative submission of a university course. "And this paper took four months or more to write, you say!?" "After seven drafts!?" It seems all somewhat absurd until we begin to discern the silence in the writing-the cultivation of one's being, from which the words begin to proliferate in haltingly issued groupings: then finally an eight, or twelve, or fifteen page paper, much less completed than interrupted, a blushing response to a call to say something worth saying, to actually say something, while being thoughtfully aware of the ease with which such speaking tends to reduce to the sometimes academic chatter of properly footnoted but merely reshuffled pieces of knowledge from the mouth or pen of the teacher-professor.

\section{Some Remarks on the Idea of Phenomenology}

What is phenomenology? There is a difference between comprehending the project of phenomenology intellectually and understanding it from the inside as it were. Merleau-Ponty (1962) remarked that we can only really understand phenomenology by doing it. As a first orientation, the idea of phenomenology will be sketched around a few introductory remarks, and then a fuller description of the nature of phenomenological research and writing will be attempted.

Phenomenological research is the study of lived experience. To say the same thing differently: phenomenology is the study of the lifeworld - the world as we immediately experience it rather than as we conceptualize, categorize, or theorize about it. Phenomenology aims to come to a deeper understanding of the nature or meaning of our everyday experiences. It asks "What is this or that kind of experience like?" Phenomenology differs from almost every other sci- 
ence in that it attempts to gain insightful descriptions of the way we experience the world. So phenomenology does not offer us the possibility of effective theory with which we can now explain and/or control the world but rather it offers us the possibility of plausible insight which brings us in more direct contact with the world.

Phenomenological research is the study of essences. Phenomenology asks for the very nature of a phenomenon, for that which makes a "thing" what it is (and without which it could not be what it is). Phenomenology is less interested in whether something actually happened, how often it tends to happen, or how the occurrence of an experience is related to the prevalence of other conditions or events. For example, phenomenology does not ask, "How do these children learn this particular material?" but it asks, "What is the nature of the experience of learning (so that I can now better understand what this particular learning experience is like for these children)?"

The essence or nature of an experience has been adequately described in language when the description reawakens or shows us the lived meaning or significance of the experience in a fuller or deeper manner.

Phenomenological research is the attentive practice of thoughtfulness. Indeed, if there is one word that most aptly characterizes phenomenology itself, then this word is "thoughtfulness." In the works of the great phenomenologists, thoughtfulness is described as a minding, a heeding, a caring attunement-a heedful, mindful wondering about the project of life, of living, of what it means to live a life. For us this phenomenological interest of doing research materializes itself in our everyday practical concerns as parents, teachers, teacher educators, psychologists, child care specialists, administrators: in short, pedagogues. As pedagogues we ongoingly must act responsibly and responsively in our relations with children, with youth, or with those to whom we stand in a pedagogical relationship. So in sorne strange sense, the theoretical practice of phenomenological research, like the mundane practice of pedagogy, is a ministering of thoughtfulness. Phenomenological pedagogical research edifies the same attentive thoughtfulness which serves the practical tactfulness of pedagogy itself.

Phenomenological research is a search for what it means to be human. As we research the possible meaning structures of our lived experiences, we come to a fuller grasp of what it means to be in the world as a man, a woman, a child, taking into account the sociocultural and the historical traditions which have given meaning to our ways of being in the world. For example, to understand what it means to be a woman in our present age is also to understand the pressures of the meaning structures which have come to restrict, widen, or question the nature and ground of womanhood. Phenomenological research is a search for the fullness of living, for the ways a woman possibly can experience the world as woman, for what it is to 
be a woman. In phenomenological research the is always implies a possible ought. If to be father means to take active responsibility for a child's growth, then it is possible to say of actual cases that this or that is no way to be a father. So phenomenological research has, as its ultimate aim, to fulfill our human nature: to become more fully who we are.

Phenomenological research is a poetizing activity. This means that phenomenology is in some ways very unlike any other research. Most research we meet in education is of the type whereby results can be severed from the means by which the results are obtained. Phenomenological research is unlike other research in that the link with the results cannot be broken, as Marcel explained, without loss of all reality to the results. And that is why, when you listen to a presentation of a phenomenological nature, you will listen in vain for the punchline, the latest information, or the big news. As in poetry, it is inappropriate to ask for a conclusion or a summary of a phenomenological study. To summarize a poem in order to present the result would destroy the result because the poem itself is the result. The poem is the thing.

So, phenomenology like poetry is a poetizing project: it tries an incantative, evocative speaking, a primal telling, wherein we aim to involve the voice into an original singing of the world. But poetizing is not merely a type of poetry, a making of verses. Poetizing is a thinking on original experience and is thus speaking in a more primal sense. Language that authentically speaks the world rather than abstractly speaking of it is a language that reverberates the world, as Merleau-Ponty says, a language that sings the world. We must engage language in a primal incantation or poetizing which hearkens back to the silence from which the words emanate. What we must do is discover what lies at the ontological core of our being. So that in the words, or maybe better, in spite of the words, we find "memories" which paradoxically we never thought or felt before.

\section{Methodology: "Doing" Phenomenological Research and Writing}

How can this phenomenological research be pursued? Reduced to its elemental methodological structure, phenomenological research may be seen as a dynamic interplay among four procedural activities:

a. turning to a phenomenon which seriously interests us and commits us to the world;

b. investigating experience as we live it rather than as we conceptualize it;

c. reflecting on the essential themes which characterize the phenomenon;

d. describing the phenomenon through the art of writing and rewriting. 


\section{Turning to the Nature of Lived Experience}

Every project of phenomenological inquiry is driven by a commitment of turning to an abiding concern. "To think is to confine yourself to a single thought till it stands still like a star in the world's sky," said Heidegger. This commitment of never wavering from thinking a single thought more deeply is the practice of thoughtfulness, of a fullness of thinking. To be full of thought means not that we have a whole lot on our mind but rather that we recognize our lot of minding the Whole-that which renders fullness or wholeness to life. So phenomenological research is a being-given-over to some quest, a true task, a deep questioning of something which restores an original sense of what it means to be a thinker, a researcher, a theorist.

A corollary is that phenomenological research does not start or proceed in a disembodied fashion. It is always a project of someone: a real person, who, in the context of particular individual, social, and historical life circumstances, sets out to make sense of a certain aspect of human existence. But while this recognition does not negate or relativize the plausibility of the insights gained from a specific piece of phenomenological work, it does show up the scope and nature of the phenomenological project itself. A phenomenological description is always one interpretation, and no single interpretation of human experience will ever exhaust the possibility of yet another complementary, or even potentially richer, description.

\section{Existential Investigation of Experience As We Live It}

Phenomenological research aims to establish a renewed contact with original experience. Merleau-Ponty showed that turning to the phenomena of lived experience means relearning to look at the world by reawakening the basic experience of the world. This turning to some abiding concern of lived experience has been called a turning "to the things themselves," Zu den Sachen (Husserl): it is a becoming full of the world; full of lived experience. "Being experienced" is a wisdom of the practice of living which results from having lived life deeply. In doing phenomenological research this practical wisdom is sought in the understanding of the nature of lived experience itself. On the one hand it means that phenomenological research requires of the researcher that he stands in the fullness of life, in the midst of the world of living relations and shared situations. On the other hand it means that the researcher actively explores the category of lived experience in all its modalities and aspects.

\section{Reflecting on Essential Themes}

The understanding of some phenomenon, some lived experience, is not fulfilled in a reflective grasp of the facticity of this or that particular experience. Rather, a true thinking on lived experience is a thoughtful, reflective grasping of what it is that renders this or that 
particular experience its special significance. Therefore, phenomenological research, unlike any other kind of research, makes a distinction between appearance and essence, between the things of our experience and that which grounds the things of our experience. In other words, phenomenological research consists of reflectively bringing into nearness that which tends to be obscure, that which tends to evade the intelligibility of our natural attitude of everyday life. About any experience or activity, whether it be mothering, fathering, reading, running, teaching, testing, leading, lending, drawing, driving, or the experience of time, space, things, the body, others, we can reflectively ask, what is it that makes this lived experience what it is?

\section{Phenomenological Describing Through the Art of Writing and Rewriting}

So we ask, what is it like to do phenomenological research? The question is not, "What is phenomenological research?" or "How do we write up our research findings?" For indeed, to do research in a phenomenological sense is already and immediately and always a bringing to speech of something. And this thoughtfully bringing to speech is most commonly a writing activity. Is phenomenological writing thought brought to speech? Or is it language which lets itself be spoken and used as thought? Experientially language and thinking are difficult to separate. When I speak I discover what it is that I wished to say, says Merleau-Ponty. And Gadamer notes how thinking and speaking, rationality and language, derive their contemporary meanings from the same root "logos." And in turn "logos" has retained the meaning of conversation, inquiry, questioning: of questioningly letting that which is being talked about be seen. So phenomenology is the application of logos (language and thoughtfulness) to the phenomenon (lived experience), to what shows itself. Or to borrow Heidegger's (1962) convoluted phrase, phenomenology is "to let that which shows itself be seen from itself in the very way in which it shows itself from itself" (p. 58).

How can the procedural dimensions of the dynamic interplay of the above four methodological themes be further pursued? The following outline details the kinds of procedural activities which dialectically are involved in phenomenological research and writing. However, no sequential order is necessarily implied in the outline-in a sense one works at all aspects at the same time.

\section{Turning to the Nature of Lived Experience}

\section{Orienting to the Phenomenon}

"Phenomenology is the study of essences," said Merleau-Ponty. But the word "essence" should not be mystified. By essence we do not mean some kind of mysterious entity or discovery, nor some ultimate core or residue of meaning. Rather, the term "essence" is 


\section{Methodological Outline for Doing Phenomenology}

\section{A. Turning to the Nature of Lived Experience}

1. Orienting to the phenomenon

2. Formulating the phenomenological question

3. Explicating assumptions and preunderstandings

B. Existential Investigation

4. Exploring the phenomenon: generating "data"

4.1 Using personal experience as a starting-point

4.2 Tracing etymological sources

4.3 Searching idiomatic phrases

4.4 Obtaining experiential descriptions from subjects

4.5 Locating experiential descriptions in literature, art, etc.

5. Consulting phenomenological literature

\section{Phenomenological Reflection}

6. Conducting thematic analysis

6.1.1 Uncovering thematic aspects in lifeworld descriptions

6.1.2 Isolating thematic statements

6.1.3 Composing linguistic transformations

6.2 Gleaning thematic descriptions from artistic sources

7. Determining essential themes

D. Phenomenological Writing

8. Attending to the speaking of language

9. Varying the examples

10. Writing

11. Rewriting: (A) to (D), etc. 
probably best understood as a linguistic construction: a description of a phenomenon. A good description that constitutes the essence of something is construed so that the structure of a lived experience is revealed to us in such a fashion that we are now able to grasp the nature and significance of this experience in a hitherto unseen way.

When a phenomenologist asks for the essence of a phenomenon-a lived experience - then the phenomenological inquiry is not unlike an artistic endeavour, a creative attempt to somehow capture a certain phenomenon of life in a linguistic description that is both holistic and analytical, evocative and precise, unique and universal, powerful and eloquent. So an appropriate topic for phenomenological inquiry is determined by the questioning of the essential nature of a lived experience: a certain way of being in the world. A phenomenological concern always has this twofold character: a preoccupation with both the concreteness (the ontic) as well as the essential nature (the ontological) of a lived experience.

Phenomenology is not concerned primarily with the nomological or invariant aspects of some state of affairs; rather, it always asks, what is the nature of the phenomenon as meaningfully experienced? For example, a phenomenological interest in the reading experience of children would be unlikely to involve experimentation with some hypothetical variable(s) or testable skills by comparing the reading experiences of children from this group, class, or school with that group, class, or school. Instead, phenomenology asks, what is the reading experience itself like for children? Or, what is it like for a young child to read? Similarly, phenomenology is less concerned with the facticity of the psychological, sociological, or cultural peculiarities or differences of the meaning structures of human experience. It is important, therefore, for the researcher to focus carefully on what it is, what phenomenon, what possible human experience is to be made topical for phenomenological investigation. This starting point of phenomenological research is largely a matter of identifying what it is that deeply interests oneself and of identifying this interest as a true phenomenon, i.e., as some experience that human beings live through. The nature and number of possible human experiences are as varied and infinite as human life itself.

For the purpose of this discussion I will use my interest in the nature of parenting as an illustrative example when discussing the various aspects of doing phenomenological research. When I am interested in the pedagogic lives that adults live with children, I may ask myself: Is it mothering or fathering I am interested in? And how is teaching like parenting in the sense that teachers function as in loco parentis? I want to use the word "parent" to point at the lived experience in which I am really interested. But what kind of care-giving to children is parenting? Are foster parents "parents" in this sense? And what about adoptive parents or other caretakers of children performing such a function? Should I allow for the possibility that not all (biological) parents know necessarily what that special mode 
of being in the world, "parenting," is like? I guess I am really asking: Is there something essential to the experience of parenting?

This kind of questioning focuses on the nature of the experience being investigated: the questioning of the identity of the phenomenon. As a father and as an educator, I have ample opportunity to have an eye for the experiences parents have. And yet, as I reflect on these experiences, it ironically becomes less clear what the experience consists of. I help my three-year-old with his breakfast or supper; we playfully create a world of blocks and toys. We go for a toboggan ride. I worry about a nasty tumble he takes on the icy snow. I tell my children a story before bedtime, I tuck them in, and then I am called back again for an extra goodnight kiss. Or maybe we are having a little chat about being afraid in the dark. Later Mom and Dad discuss the wisdom of early music lessons and what to make of Mark's reaction to one of his friends. Is this parenting? Of course it is! But how so? In what sense are these experiences examples of parenting? Do parents play with their children differently than the way any person may happen to play with a child? Would not a trained teacher tell or read a story to my child better than I possibly could? Is there a difference between the way parents talk with and about their children and the way others may talk with or about these children? Things turn very fuzzy just when they seemed to become so clear.

To do a phenomenological study of any topic, therefore, it is not enough to simply recall experiences others or I may have had with respect to a particular phenomenon. Instead I must recall the experience in such a way that the essential aspects, the meaning structure of this experience as lived through, are brought back, as it were, and in such a way that we recognize this description as a possible human experience, which means as a possible interpretation of that experience. This then is the task of phenomenological research and writing: to construct a possible interpretation of the nature of a certain human experience. In order to make a beginning, the phenomenologist must ask, what human experience do I feel called upon to make topical for my investigation?

\section{Formulating the Phenomenological Question}

It is not until I have identified my interest in the nature of a selected human experience that a true phenomenological questioning is possible. To do phenomenological research is to question something phenomenologically and, also, to be addressed by the question of what something is "really" like. What is the nature of this lived experience? In the case of my example: What is parenting like? What is it like to be a mother? Or a father? To ask for the nature of parenting is to ask for the whatness of parenting. What is it about my experiences of being a father to this child that makes me a parent? What does this child mean to me and what do I mean to this child? What is it about parenting that makes it possible for parenting to be what it 
is in its isness or essence? An important reminder for all phenomenological research, in all its stages, is to be constantly mindful of one's original question and thus to be constantly oriented to the lived experience that makes it possible to ask the "what it is like" question in the first place. So I am asking, what is it about parenting that renders the experience of mothering, fathering, and so forth their pedagogic significance? When I ask, What is the essence of parenting? I seem to ask what is this pedagogic ground of parenting? So, for the purpose of my example, I will settle on this formulation: "What is the pedagogy of parenting?" But in so doing, I will take this to mean that I wish to come to a deeper understanding of what it is about fathering, mothering, grandparenting, teaching, foster-parenting such that this mode of being with children is that which I wish to understand as parenting. And, of course, I must not assume that the experiences of mothering and fathering are the same. So what is it like to be a mother? A father?

The essence of the question, said Gadamer (1975), is the opening up, and keeping open, of possibilities. But we can only do this if we can keep ourselves open in such a way that in this abiding concern of our questioning we find ourselves deeply interested (inter-esse, to be or stand in the midst of something) in that which makes the question possible in the first place. To truly question something is to interrogate something from the heart of our existence, from the centre of our being. Even minor phenomenological research projects require that we not simply raise a question and possibly soon drop it again, but rather that we "live" this question or, better, that we "become" this question. Is this not the meaning of research: to question something by going back again and again to the things themselves until that which is put to question begins to reveal something of its essential nature? I can only genuinely ask the question of the nature of parenting if I am indeed animated by this question in the very life I live with children.

Moreover, every form of research and theorizing is a thoroughly ethical activity in that theorizing about some aspect of our pedagogic living with children, young people or adults is already the showing of a form of life. We cannot ask questions about the lives of children without it in some way affecting the very lives of those whom we make the topic of our research.

But how can a phenomenological question that makes us wonder and write about a certain phenomenon be treated in a phenomenological description? In most forms of research, the question that animates the research is stated unequivocally. In experimental research the question is formulated as a null hypothesis. The cleaner and less ambiguous the research question, the less ambiguous the interpretation of the research findings. In much social and human science research, it is assumed that a productive research question is formulated in such a clear-cut and prosaic manner that any competent and "disinterested" social or behavioral scientist can deal with 
the question. That is why so much research can be contracted out to research teams or agencies. The matter lies quite differently with phenomenological research.

A phenomenological question must not only be made clear, understood, but also "lived," as it were. A phenomenological researcher cannot just write down his question at the beginning of his study. There it is! Question mark at the end! No, in his phenomenological description he must "pull" his reader into the question in such a way that the reader cannot help but wonder about the nature of the phenomenon in the way that the phenomenologist does. One might say that a phenomenological questioning teaches the reader to wonder, to question deeply the very thing which is being questioned by the question. Sometimes this involves avoiding posing the question outright because it leads the reader to misinterpret or underestimate its probing nature. Instead, one might, at the hand of a concrete story, draw the reader into a questioning mood with respect to the topic being addressed. Compare, for example, Heidegger's essay on language. Heidegger asks, What is language? without ever reducing the question to such prosaic formulation. At other times one may have to discuss reflectively how a question is difficult to ask for we may have forgotten what lies at the core of the question (see section 4.2).

\section{Explicating Assumptions and Pre-Understandings}

The problem of phenomenological inquiry is not always that we know too little about the phenomenon we wish to investigate but that we know too much. Or, more accurately, the problem is that our "common sense" pre-understandings, our suppositions, assumptions, and the existing bodies of scientific knowledge predispose us to interpret the nature of the phenomenon before we have even come to grips with the significance of the phenomenological question. Another way of stating this is that scientific knowledge as well as everyday knowledge believes that it has already had much to say about a phenomenon, such as what the phenomenon of parenting is, or what parents do or should do, before it has truly come to an understanding of what it means to be a parent in the first place. How do we best suspend or bracket these beliefs? If we simply try to ignore what we already "know," we may find that the presuppositions persistently creep back into our reflections. It is better to make explicit our understandings, beliefs, biases, assumptions, presuppositions, and theories in order then to simply not try to forget them again but rather to turn this knowledge against itself, as it were, thereby exposing its shallow or concealing character.

As I explore the literature by specialists of parenting, I note how the large majority of books do not address the question of what parenting is, but rather they tend to beg the question in that they tend to give advice to mothers and fathers of children of all ages. I notice too that parenting is often considered a "how to do" skill that 
can be taught: popular books are entitled Parent Effectiveness Training, How to Deal With Your Hyperactive Child, What to Do with Your Growing Adolescent, Tough Love and so forth. No matter how practically compelling the contents of these books may be, they do not necessarily bring us any closer to understanding the nature of parenting itself.

In the research literature four metaphors have dominated the study of parenting. At the time when child psychologists thought that the newborn had only primitive sensory functions, parents were advised to provide good physical care for their babies, but the baby's room was a sterile and empty place fitted only with crib and baby bottles. Good parents were seen to be people who took good care of the physical needs of their children. Even "mother" love was translated into something physical (witness the wire versus the cloth mother-monkey experiments in Harlow's well-known studies of the importance of "touch"). And yet it was studies such as the ones by Harlow, Bowlby, and Spitz that led to the rediscovery of the importance of breast-feeding for both nutritional and bonding reasons. Even today many lay people believe that babies, for a few weeks or months at least, are incapable of being very perceptive of their environment. So the essence of parenting at one time was seen to consist primarily of the job of providing physical care.

This metaphor of the body shifted towards the mind as it was replaced with the notion that parenting essentially consists of a set of attitudes, a minding, a certain disposition we adopt toward our children. For example, mothers were told that maternal love and appropriate affections are critical in normal healthy development.

Next, in a move back to the body, but now purged of its banal functions, emerged the metaphor of parenting as stimulation: a spurring and goading of a passive-reactive child by means of behavioral techniques and stimulating environments. To be a good parent meant, for example, to reinforce positive behaviors by means of behavioral rewarding techniques.

The most recent metaphor is borrowed from linguistics. It defines the essence of parenting as interlocution or dialogue. Psychologists have discovered, with the aid of slow playback split-screen video recordings, the incredible variety and subtlety of infant interaction and communication with the mother. This has led to new theories of the importance of physical, face-to-face, or eye contact that infants have with those who take care of them. But what does this say about the nature of parenting?

It would appear that the foundational element in research thinking on the essence of parenting largely consists of trading metaphor for metaphor in the attempt to find the common denominator. The research efforts initially focus on exploiting the productive elements of a certain conception of the essence of parenting. In time-for whatever ideological reasons or sociohistorical circumstances-this 
conception gets to be seen as merely one of its various aspects. In other words, what was once considered essential now is merely an aspect or a view, while the deep meaning of these aspects remains out of reach.

Psychologists who are engaged in research on parenting seem to know this. After reviewing the results of decades of research on parenting, Schaffer (1977) concludes that, in spite of all these research efforts, the question of the nature of parenting is still an unsolved problem. "Something essential is missing," he says. And he continues, in a sobering sort of way: "Ask any mother what she considers to be the essence of mothering and she will have no hesitation in replying: love. And yet, curiously," says Schaffer, "mother love has not yet become researchable" (p. 79). Schaffer may be right, but even those who feel that the essence of parenting lies in the "unreachable" neighbourhood of love cannot escape a certain epistemological nihilism. In a scientific sense, we may not know (yet) what love is. No matter. Maternal and paternal love have been described as nothing more than a culturally sponsored phenomenon. At best, mother-love is simply socially learned behavior, and at worst, some modern feminists say it is an historical conspiracy of man to snare woman in an artificial bondage to her children and spouse. It would seem that it is such epistemological nihilism which forces us to always see the relative, historical, constructed, and social character of all truth at the expense of its deep hermeneutic facticity.

But more disconcerting from a phenomenological point of view is the reminder that love too is only a metaphor for parenting. The word is more telling about the way we account for certain (affectionate) interactions than that it truly lays bare the deep meanings of those interactions. Nietzsche once observed that all language, and therefore all truth and error, is metaphoric in origin. Virtually every word we utter ultimately derives from some image thereby betraying its metaphoric genesis. Our most prized certainties, our best proven ideas, our most neglected commonplaces must admit to their metaphoric geneology. But does this metaphoric origin of speech render all truth regarding parenting arbitrary? Are truth and error sister and brother? Does this mean that there is no way that we can know anything essential about parenting? Does this mean that there is no ground, no primordiality, which engenders and sponsors these siblings? And so all we would ever be able to do is to uncover the latest metaphor about parenting and unmask its perspectival nature. This indeed seems to be our predicament.

But metaphor is not simply the bottomless ground, the empty core, the final destination of language. By way of metaphor, language can take us beyond the content of the metaphor towards the original region where language speaks through silence. This is the speaking of thinking, of poetizing. Virginia Woolf once described how words not only find their semantic limit in metaphor; metaphor is also language's way of making it possible for the poet to transcend this limit: 
By the bold and running use of metaphor, the poet will amplify and give us not the thing itself, but the reverberation and reflection which, taken into his mind, the thing has made; close enough to the original to illustrate it, remote enough to heighten, enlarge, and make splendid. (1932, p. 32)

What does it mean, then, to have an understanding of what belongs to the essence of parenting? Maybe the primordiality of the pedagogy of parenting is much less something we can discover, construct, or identify by naming or conceptualizing it. Rather, the very idea of the primordial signifies that the pedagogy of parenting is something that must be brought back, recalled, or recollected from original experience. The pedagogy of parenting in this sense is, as Marcel might have said, not a problem in need of a solution but a mystery in need of evocative comprehension. To evoke the mystery of the pedagogy of parenting is, therefore, much less to attempt to unravel a problem than to try to recapture something: to reachieve a direct contact with the world of living with children by awakening the soul to its primordial reality.

But, by terming pedagogy or parenting essentially a "mystery," are we therefore assigning less substance, less reality to it? Not at all. The mystery of parenting is knowable. We know it, one might say, in the way we cannot deny the reality of our feelings, intuition, conscience, will, mood. Parenting is not simply an entity, not a certain form of behavior, not even a feeling or an emotion like "love" or "care." And yet we sense this presence that we call mothering or fathering in our pedagogic lives with children. And this is because pedagogy announces itself not as entity, behavior, feeling, or emotion but through them. Parenting is utter mystery, yet knowable. The project of a phenomenology of parenting is, therefore, not to translate (reduce) the primordial relation of parenting into clearly defined concepts so as to dispel its mystery, but rather the object is to bring the mystery more fully into our presence. Such a project has to make use of language in such a way as to make present to us what is inherently pre-linguistic and therefore essentially not transposable into a set of precisely delineated propositional statements.

But before completing this section, we must reflect further on the assumptions of parenting as love or care. Psychologists have argued that it is not quantity but quality of parental care that matters for child development. This should be reassuring because ever-growing numbers of young children spend the "better" part of their waking hours in daycare institutions while their parents are at work. And yet, despite the stimulating educational nature of gocd daycare environments, it is not clear whether daycare workers can or should provide "parenting experiences" to those entrusted to their care. Can daycare workers provide parental care to children? What does parental love mean for the child if some other person (grandparent, foster-parent, teacher, or daycare worker) "stands in" for the "true" parent as expressed in the term in loco parentis? Is the biological parent automatically the (only) true parent? These and other ques- 
tions help me to recognize not only the limits of prevalent beliefs, but also the manner in which I am personally inclined to question these beliefs.

\section{Existential Investigation}

\section{Exploring the Phenomenon: Generating "Data"}

In the literature the aspect of existential investigation in doing phenomenological research has been called "generating data." But such a phrase has an objectivistic quality to it which is rather inappropriate for phenomenology. The phrase "generating data" might suggest, for example, that this is a separate stage, or that someone else could conceivably do this more mechanical part of the research while the main investigator manipulates and interprets the "findings," as is sometimes done in experimental or survey research. From a phenomenological point of view it would be more appropriate to see this part of the research process as the educational development of the researcher: that is, finding ways to develop deeper understandings of the phenomenon being investigated. It usually consists of a thorough exploration of the scope of lived experience, of the kinds of material that can be found and which might eventually have a bearing on the possibility of developing a deeper understanding of the nature of the phenomenon.

This researching of the phenomenological question goes significantly beyond the type of protocol or data collecting from subjects (by means of interview or written protocols) as suggested by some human science researchers. The challenge of this exploratory work is that, while interpretive material is located (or stumbled upon), the researcher is sensitive to the ways in which this material begins to speak, as it were, and yet all the while remaining open to new material and to other interpretive possibilities. The exploratory and interpretive work of this "stage" and the interpretive work of the next "stage" are in reality much more interwoven than the neat separations which this or any methodological discussion may suggest. Material that may eventually yield significant interpretive understandings can be sought in a variety of places: one's personal experiences, the etymology of relevant terms, idiomatic phrases and expressions, other people's experiences, biographies or reconstructed life stories, experiential descriptions contained in artistic and literary sources, and so forth.

Broadly speaking, phenomenologists educate themselves in two fundamental directions: First, they know the importance of having had real life experiences, of being experienced, of standing in the middle of life, of having a sense of practical wisdom that comes from working and living with those (children, youths, or adults) in whose lives they have pedagogical interest. All understanding is ultimately self-understanding. The less life experience the phenomenologist has developed, the more crucial it is that one gains the experiential understanding from extensive and time consuming field work: inter- 
viewing, observing, playing, talking with subjects, case studies, involving oneself in participatory work, and so forth. For example, one gains real life experiences about children, not by observing them from a distance by way of test instruments, or through a one-way mirror, but by living with them, striving for the kind of contact and dialogue that helps us to understand what a certain experience is like for children.

Secondly, the phenomenologist knows the value of having read widely and deeply and of having an insatiable interest in the ways in which sensitive artists are providing us vicariously with expressive examples of fundamental truth experiences. There exists a hermeneutic dialectic between lived life and art: art interprets life and life interprets art. Indeed, from a phenomenological point of view we may gain more interpretive understanding and more profound insights into human life from a great novel or a great poem than from some reputable behavioral social science text.

\subsection{Using Personal Experience as a Starting-Point}

The ego-logical starting point for phenomenological research is a natural consequence of the above remarks. My own life experiences are immediately accessible to me in a way that no one else's experiences are. However, the phenomenologist does not want to trouble the reader with purely private, autobiographical facticities of one's life. The revealing of private sentiments or private happenings are matters to be shared among friends perhaps, or between lovers, or in the gossip columns of life. In drawing up personal descriptions of lived experiences, the phenomenologist knows that one's own experiences are also the possible experiences of others.

To conduct a personal description of a lived experience, I try to describe my experience as much as possible in experiential terms, focusing on a particular situation or event. I try, as Merleau-Ponty says, to give a direct description of my experience as it is, without offering causal explanations or interpretive generalizations of my experience.

I'll try to give a personal, experiential account of the beginning of my fatherhood. How did "having children" enter my life? I remember several occasions when friends of ours would speak of the deep satisfaction of having young children of their own. How it changed their way of looking at life and at the world. I always thought I understood what they were saying (now I know that I did not). I countered that I felt no lack, no need for a family and argued, eloquently, I believe, how the children I taught at school gave me similar satisfactions without having to "possess" some of my own. I felt a strong, almost physical dislike for the idea of fatherhood, and privately considered my friends to be quite foolish. Talking to young parents is like talking to religious converts, I said to Judith, my wife. As we would return home, we would talk about how we prized ourselves lucky to be able to enjoy each other, our quiet, our books, and our freedom to do what we liked and to go where we pleased. Very occasionally Judith would speak of her doubt about our resolve not 
to have children. I always resisted the discussion convincingly. I was thirty-something and felt young.

One day we visited Judith's cousin, who had just given birth to her third child. I recall the chaos of the home-food smells, crackers, junk, stains, toys, and blankets. Altogether I felt somewhat repulsed at the greasiness of the child scene-such contrast to our home or my classroom. One moment stands out clearly. My wife had taken the newborn baby in her arms and then I felt strangely moved-she and this baby, so lovely-it seemed right, good. The next time the topic of having children came up (I might have brought it up myself), I still resisted, but weakly. I doubted my ability to be an enthusiastic father. I told Judith a last time that I distrusted the world we live in; it seemed so foolish, so egotistical to put children in this madness. Secretly, I could hardly wait for our first child to be born. Yet at times I felt afraid. What if I could not love this child Judith was bearing? Feeling guilty, I only admitted my uncertainties to myself while talking supportively to my wife.

It is to the extent that my experiences could be our experiences that the phenomenologist wants to be reflectively aware of this. To be aware of the structure of my own experience of this phenomenon may provide me with clues for orienting myself to the phenomenon and thus to all the other stages of phenomenological research. In actual phenomenological descriptions one often notices that the author at times uses the "I" form or the "we" form. This is done not only to enhance the evocative value of a truth experience expressed in this way, but also to show that the author recognizes both that one's own experiences are the possible experiences of others and that the experiences of others are the possible experiences of oneself. Phenomenology always addresses any phenomenon as a possible human experience; this is why phenomenological descriptions have a universal (intersubjective) character.

\subsection{Tracing Etymological Sources}

The first thing that often strikes us about any phenomenon is that the words we use to refer to the phenomenon have lost some of their original meaning. Words that once could invoke and reveal a world now are mute, emptied and forgetful of their past power. What can still be conveyed by words such as "earth" or "water," "happiness" or "hope"? How flat words like "parent" or "teacher," "home" or "school," "knowledge" or "care" have become. Note, for example, how nowadays the word "caring" is being overused by social work, medical, legal, educational, and counselling professionals. And this occurs right at the time when we no longer seem to know what it means to truly care. We speak of medicare, daycare, legal care, health care, after school care, and so on. We hope to meet caring doctors and caring teachers for our children. But do we still know how to connect these social service professions with the original meanings of "care" as sorrow? Of course, retrieving or recalling the essence of caring is not a matter of simple etymological analysis or explication of the usage of the word. Rather, it is the reconstruction of a way of life: A willingness to live the language of our lives more deeply, to be- 
come more truly who we are when we refer to ourselves, for example, as teachers or parents.

To be attentive to the etymological origins of words can sometimes put us in touch with the original form of life where the terms still had living ties to the lived experiences from which they originally sprang. It can be shown, for example, that the words "parent," "child," "baby," "womb," and "birth" are all closely related to the verb "to bear" as in the experience of pregnancy, childbirth, as well as in the very experience of parenting as providing spaces that bear children, spaces where children live and exist as children.

The etymology of the word "parenting" refers to both "giving birth to" and "bringing forth." Strongly present is the connotation of origin or source. To parent (parere) is to originate, to be the source, the origin from which something springs. How is this sense of source maintained in the experience of parenting? I may feel the pride and recognition of having brought this child into the world, but at the same time I know a deeper recognition: that it was not I who helped produce this child but rather something other and "larger" than me that made it possible for me to have this child in the first place. And so my experience of pride, as new father or mother, is tempered by the strange sense that I much less produced this child than that it came to me as a gift. My pride is then really a pride of being worthy of this gift that comes as if it were I who brought the child into being. And here is the theme of the effect which, in a deep sense, the child has on the mother and the father. The child is not simply received as a gift for which we make room in our lives. As Marcel expressed it, the truth is much more, that the gift is a call to which we have to make a response. Parents bring forth children, but the child must be born in the dual sense of bearing and birth, bringing and awakening to the world.

The English word "child" can be traced to the Gothic kilthe, meaning womb. Similarly, words akin to the term "baby" are translatable as the borne one, the one who is carried in the womb. An old word for "child" is still preserved in the Lowland-Scots "bairn," cognate with Anglo-Saxon "bearn," meaning bearing and born. In my native Dutch language the word for "womb" is baarmoeder, literally "mother who bears," mother who holds, carries the child. So both childbearing and the giving birth are aspects of the same verb "to bear." In these persistent etymological references to bearing and safe-keeping of the child, we may find clues to the deep meaning of parenting and of teaching as in loco parentis. In providing bearing for their children parents give and teach the very young something without which growing up or even the living of a life becomes quite impossible. Parents who bear, give bearing to children, make available space and ground for being. They teach their children that the world can be experienced as home, a place for safe dwelling, a habitat where human beings can be, where we can be ourselves, where we can have habits: ways of being and doing things. 
So to bear children is, in a broad sense, to provide place and space for them to live, to be. The child is carried, borne inside the womb at first, then it is born into the world where it remains, for a while at least, most helpless, dependent, in need of nurture, warmth, caress, holding-fast, and safe as an embryo outside the womb. It is in the face of the worldly experience of separateness, lostness, without a bearing, without the security of safe ground that the primordial nature of parenting can be intuited.

\subsection{Searching Idiomatic Phrases}

It is sometimes surprising how didactic language itself is if we allow ourselves to be attentive to even the most common of expressions associated with the phenomenon we wish to pursue. This should be no surprise since idiomatic phrases largely proceed phenomenologically: they are borne out of lived experience. For example we say, "every child needs a home."

In the concept of home or dwelling there is a strong sense of watching over something, preserving a space where the human being can feel sheltered, protected, and what is thus preserved in the idea of a house with its wall and fences is a safe keeping, holding, or bearing of something which needs to be watched over. This caring modality of parenting, this nurturing, sheltering, and providing protective ground for the child, is not something theoretical that needs to be proven or tested as our response to the child's experiences of fear and being afraid. Rather, it is something primordial which defies literal language and precise definition.

Ordinary language is in some sense a huge reservoir where the incredible variety of richness of human experience is deposited. The problem often is that these deposits have silted, crusted, or fossilized in such a way that the original contact with our primordial experiences is broken. For example, of the reading experience we say of someone that she is "lost in a book." But what does this expression reveal? Is the reader truly lost? While absorbed in a book a reader may lose her sense of time, place, body, etc. Who has not had the experience of showing up late for supper, an appointment, or missing a bus stop because of being lost in a book? But in another sense, the reader who is lost in a story is not lost at all. We may be temporarily "absorbed" in a different world from that of the one who made the remark, but the reader lacks nothing, misses nothing, needs nothing; that is why the reading experience is so absorbing. The person who is much more nearly lost is the person who made the remark. Indeed when a husband says of his wife that she is lost in a book, then $h e$ is the one who experiences a loss, namely the attentive presence of his spouse. The expression "she is absorbed in a book" can show us more clues of the nature of the reading experience. It raises the question of the meaning of the sense of spatiality which belongs to the text. What is the nature of reading space? And how is the experience of this space related to the experience of the space where 
we see the reader sitting while submerged in the book? What is it about a space that makes it a good place to read? And what is the nature of the time experience and the experience of one's body in those different dimensions?

Similarly, with respect to the phenomenon of parenting, what other expression might provide helpful occasions for phenomenological reflection on the lived experiences from which the expressions derive their meaning? This can be an important (but often neglected) aspect of phenomenological "data collecting." We say "like mother, like daughter" or "like father, like son." What could be the experiential significance of this phrase? The word "mother" is associated with a variety of expressions: "mother earth," "mother language," "mother tongue," "mother nature," etc. We speak of "fatherland," "forefathers," etc. And the word "parenting" is often used to connote "creating," "originating," "begetting," "to be the source of something." The point is not that one blindly collects a multitude of linguistic items associated somehow with the phenomenon, but that one reflectively holds on to the verbal manifestations that appear to possess interpretive significance for the actual phenomenological description. Idiomatic language (as well as the language of writers and poets) is an inexhaustible source for phenomenological analysis.

\subsection{Obtaining Experiential Descriptions From Others}

In phenomenological research the emphasis is always on the meaning of lived experience. The point of phenomenological research is to "borrow" other people's experiences and their reflections on their experiences in order to better be able to come to an understanding of the deeper meaning or significance of an aspect of human experience, in the context of the whole of human experience. So in the phenomenological investigation of the experience of parenting, we wish to understand what being a parent is like for this or that person as an aspect of his or her life and, therefore, by extension, as an aspect of the possibilities of our being human.

To gain access to other people's experiences, I might request them to write about a personal experience. I ask: Please write a direct account of a personal experience as you lived through it. Avoid causal explanations or interpretive generalizations.

Here is an example:

Lately I have been wondering if I expect too much of my son. He gets all mixed up in his homework, is overtired, can't think straight, and spends hours doing one straightforward assignment when he should just be relaxing and enjoying family life like all the other kids in his class: he has misread the instructions and has to do the whole thing again; he has a thousand ideas for a report on gorillas, but can't seem to get it together to write even the opening sentence. So yesterday I looked at Robbie's cum-file at school. I felt guilty in a way, resorting to that, especially since those numbers have so little to say about a person. And my love and 
hopes for him are unconditional of course, don't depend on his achievement or IQ scores. But the numbers weren't supposed to tell me whether Rob is special or not-they were supposed to tell me whether it is alright for me to tease, prod and cajole him about his homework, and say, "Hey, you lazy schmuck, get some of this work finished in school instead of fooling around," or maybe, "Of course, you can't think straight when you're so tired. You'll have to get home earlier and do this homework before supper."

Another way of collecting accounts of personal experiences is to have taped conversations with people who might tell us personal life stories. Sometimes it is easier to talk than to write about a personal experience because writing forces the person into a more reflective attitude which may make it more difficult to stay close to an experience as it is immediately lived.

As we interview others about their experience of a certain phenomenon, it is imperative to stay close to experience as lived. As we ask what an experience is like, it may be helpful to be very concrete. Ask the person to think of a specific instance, situation, person, or event. Then explore the whole experience to the fullest. Naturally, it is impossible to offer ready-made questions. For example, if we were to interview women about the process of becoming mothers, we may wish to begin at the very beginning with questions such as, "How did the idea of having children first arise?" "Or did it?" "Who said what?" "How did you feel about that?" "You say that you caught yourself looking at children differently?" "In what way?" "Can you give an example?" "What was it like to discover that you were pregnant?" "How did you become aware of it?" "What did it feel like?" "What was it like to meet or tell others?" "How did you announce it to your spouse?," etc.

Often it is not necessary to ask so many questions. Patience or silence is a more tactful way of prompting the other to gather recollections and proceed with a story. But if there seems to be a block, then it is often enough to repeat the last sentence or thought in a questioning sort of tone and thus trigger the other to continue. "So you say that people began to look at your stomach instead of your face ...?" And whenever it seems that the person being interviewed begins to generalize or opinionate about the experience you can insert a question that turns the discourse back to the level of lived experience: "Can you give an example?"

With young children, it is even more difficult to obtain personal experience descriptions. To gain access to the experience of young children, it may be important to play with them, talk with them, puppeteer, paint, draw, follow them into their play spaces and into the things they do while remaining attentively aware of the way it is for children.

But why do we need to collect the "data" of other people's experiences? We gather other people's experiences because it allows us, in a vicarious sort of way, to become more experienced ourselves. We 
are interested in the particular experiences of this child, this adolescent, or this adult since it allows us to become "in-formed," shaped or enriched by this experience so as to better be able to render the full significance of its meaning.

Traditionally, techniques used to obtain "data" from "subjects" are by way of interviewing, eliciting written responses, participant observation, and so forth. Phenomenological research may proceed along similar lines with some important qualifications, however. From a phenomenological point of view we are not primarily interested in the subjective experiences of our so-called "subjects," or "informants," for the sake of being able to report on how something is seen from their particular view, perspective, or vantage point. Of course, we may want to know what "mothering" or "fathering" is like from the viewpoint of the single parent, or the bereaved parent, or from the perspective of working class parents or more well-to-do parents who employ nannies or babysitters, and so forth. However, the deeper goal, which is always the thrust of phenomenological research, remains oriented to asking the question of, "what is the nature of this phenomenon (parenting) as an essentially human experience."

To bring the difference between phenomenology and other so-called qualitative research approaches (such as ethnography, ethnomethodology, symbolic interactionism, conceptual analysis, etc.) better into focus, we should recognize the force of the essential phenomenological question. No matter how any particular parent (or group of parents) relates to a child, we always want to know: How is this parenting? Is this what it is like to parent? Is this what it means to be a mother or father? Similarly, when we teach reading to young people, we ask: How is this reading? and teaching? Is this what it means to read? Is this what the reading experience is like?

\subsection{Locating Experiential Descriptions in Literature, Art, etc.}

"Good" literature, poetry, or other art-forms may serve as a resource of experiences to which the phenomenologist may turn to increase practical insights. The phenomenological value of a novel, for example, is determined by what may be called the perceptiveness and the intuitive sensitivity of the author. Phenomena such as love, grief, illness, faith, success, fear, death, hope, struggle, or loss are the stuff of which great novels are made. The titles of some celebrated works, such as Crime and Punishment, Nausea, The Trial, Remembrance of Things Past, announce fundamental life experiences which are available to our interpretive reading. In reading Sartre's novel Nausea, I cannot help but feel invaded by the same mood which inhabits Roquentin. And so the reader finds the experience of everyday life irresistibly shifted to the world of the novel where such fundamental life experiences are lived through vicariously. As I identify myself with the protagonist of a story, I live his feelings and actions without having to act myself. Thus I may be able to experi- 
ence life situations, events, and emotions that I would normally not have. Through a good novel, then, we are given the chance of living through an experience that provides us with the opportunity of gaining insight into certain aspects of the human condition. Works of art provide us with possible human experiences.

For the purpose of a phenomenological study of parenting, I might be interested in, for example, Phyllis Chesler's With Child: A Diary of Motherhood. The following excerpt, I believe, contains some fundamental themes of the nature of mothering (see 6.2). The text is evocative, transcending the auto-biographic style of diary-writing.

Last year I died. My life without you ended. Our life together-only nine months!-ended too: abruptly and forever, when you gave birth to me. Being born into motherhood is the sharpest pain I've ever known. I'm a newborn mother: your age exactly, one year old today.

I've dropped ten thousand years down an ancient well. My own life threatens to peel off: insignificant, recent. My stomach knots, my nails redden, to break my fall. Screaming.

I write this book to chart my descent. To slow my descent.

And to thank you for coming. Little ancestor, sweet baby! How you temper me, deepen me, like an ancient smithy working slowly. You-who need everything done for you-are the most powerful teacher I've ever known.

Last night, lying in a hot, white-foamed tub, I was suddenly pregnant with you again. I wept, aware that you no longer slept beneath my heart.

It was you-Ariel!- -in there, in me. I didn't know that. Will I grow sad every year in winter, when you leave me to be born?

This soft belly, rounded still, with your footprint. Proof of your origin, your passage through. Here, here is where you walked, without setting foot to earth. Your first moon, little astronaut.

Because of you, I'll return to Earth, transformed: no longer a virgin, but a mother, married to a child.

Together we have engaged in alchemy.

Know, Ariel: We have always been separate. While I was pregnant.

During labor. From the moment you were born. Always I had some sense of your utter separate reality.

And who could be closer than we two?

\section{Consulting Phenomenological Literature}

Whereas literature and other artistic sources can provide us with powerful experiences and insights normally out of range of the scope of our personal everyday experiences, phenomenological literature may contain material which has already addressed in an interpretive manner the very topic or question which preoccupies us. Thus, the work of other phenomenologists turns into a source for us with which to dialogue. Selected phenomonological materials enable us to reflect more deeply on the way we tend to make interpretive sense of lived experience and, thus, to transcend the limits of our interpretive sensibilities. For example, both M. J. Langeveld and G. Marcel have written about fatherhood. And both have written about the 
process of becoming a father as a kind of affirmation. Langeveld writes of the importance of commitment and active involvement of the father in the child's life, and Marcel writes about the essence of fatherhood as a "creative vow."

\section{Phenomenological Reflection}

\section{Conducting Thematic Analysis}

Phenomenological themes are the structures of experience. So when we analyze a phenomenon, we are trying to determine what the themes are, the experiential structures that make up that experience. It would be wrong, however, to think of themes as conceptual formulations, or categorical statements. After all, it is lived experience that we are attempting to describe and lived experience cannot be captured in conceptual abstractions.

\subsubsection{Uncovering Thematic Aspects in Lifeworld Descriptions}

So phenomenological themes are more like knots in the webs of our experiences, around which certain lived experiences are spun and thus experienced as meaningful wholes. Themes are the stars that make up the universes of meaning we live through. It is by the light of these themes that we can navigate and explore such universes.

Themes have phenomenological power when they allow us to proceed with phenomenological descriptions. For example, when we are interested in the phenomenology of "reading a novel," we may soon notice some possible themes: (1) When we read a book, we enter it, as it were; (2) Reading a novel means that we begin to care for the people who make up the novel; (3) While we read a story we experience action without having to act; (4) When we interrupt a book, we exit the world created by the word, etc. These kinds of themes are only fasteners, foci, or threads around which the phenomenological description is facilitated.

Let us take the example of parenting again. In what way are the themes of mothering different from the themes of fathering? Or is the experience of mothering and fathering in principle the same phenomenon? An obvious and immediate difference between mothering and fathering is the nature of the initial relationship between parent and child. A child is "given" to the mother in a different way than a child is "given" to the father. Whereas a man has to acknowledge a child as his, a woman already has the child before she can accept or reject the newcomer. The experience of a new father seems to be such that, in order to become a father, he has to accept, to say "yes" to a child; whereas a woman, already a mother by virtue of bearing and giving birth to the child, can only say "no." A woman who is pregnant is literally inhabited by the child, and so she experiences a knowledge of the child which is more symbiotic than the way a man initially knows his child. 
The question is now, how do we capture this experiential difference in a thematic manner? We might say that the experience of becoming a father includes the theme of "accepting" or "affirming" the child as his. But how is this experience lived? Both Langeveld and Marcel have provided descriptions of this theme (see section 5). Does a man have to "decide" or "agree" to take up his responsibility as a father by making a "commitment" to a newly born? The experience itself appears much less rational, less deliberate. A commitment is much less "made" than encountered. The theme of commitment is experientially there when the man takes the child in his arms, and in the gesture of accepting and holding the child, the man finds himself face to face with "responsibility," with something utterly new: often a profoundly moving experience-now he is the father of the child. But to be a father, he has to continue acting as father as well.

The point of all this is that no conceptual formulation or a single statement can possibly capture the full mystery of this experience. So a phenomenological theme is much less a singular statement (concept or category) than an actual description of the structure of a lived experience. As such, a so-called thematic phrase does not do justice to the fullness of the life of a phenomenon. A thematic phrase only serves to point at, to allude to, or to hint at, an aspect of the phenomenon.

\subsubsection{Isolating Thematic Statements}

We have noted already that lived-experience descriptions can be found in a multitude of forms: in transcribed, taped conversations; in interview materials; in daily accounts or stories; in suppertime talk; in formally written responses; in diaries; in passing comments; in reflections on other people's writings; in accounts of vicarious experiences of drama, film, poetry, or novels; in the play-acting of little children; in the talk that accompanies bed-time story-telling; in heart-to-heart conversations among friends; and so on. Naturally, some types of descriptions of lived experiences are more difficult to gather than others, but those that are in written form are often easier to work on.

Any lived-experience description is an appropriate source for uncovering thematic aspects of the phenomenon it describes. But it is true that some descriptions are richer than others. It confirms our experience that in our conversations or dialogues we tend to learn more about life from some people than from others. Nevertheless, when a person shares with us what a certain experience is like for him or her, then there will always be something there for us to gather. ${ }^{3}$

Generally we can take two approaches toward uncovering thematic aspects of a phenomenon in some text. One is the highlighting approach. The other one is the line-by-line approach. Both approaches 
should be used if possible. In the highlighting approach we listen to or read a text several times and ask, "What statements or phrases seem particularly essential or revealing about the experience being described?" These statements we then circle, underline, or highlight. In the line-by-line approach we look at every single sentence and ask, "What does this sentence or statement reveal about the experience being described?" As we thus study the lived-experience descriptions and discern the themes that begin to emerge, we note that certain experiential themes recur as commonality or possible commonalities in the various descriptions we have gathered. We hold on to these themes by lifting appropriate phrases or by capturing in singular statements the main thrust of the meaning of the themes.

For example, in the personal experience description by the mother of eight-year-old Robert (see p. 55, section 4.4), we note that the theme that seems to emerge is the one of "having expectations" about a child's (school) life and future. In experiential accounts from other mothers and fathers this theme recurs again and again.

Sentence (1) shows how we have parental expectations as well as doubts about them.

Sentence (2) shows how particular situations, occurrences, or events give meaning to our expectations.

Sentences (3) and (4) show how we try to check our expectations by trying to look at a child differently.

Sentence (5) shows that underlying the specific expectations we may cherish, there lies a more fundamental sense of hope.

Sentences (6) and (7) show how this sense of hope gets enacted in everyday life expectations.

\subsubsection{Composing Linguistic Transformations}

As we gain themes and thematic statements from our various sources, we may wish to capture the thematic statements in more phenomenologically sensitive paragraphs. This is a process of writing notes and paragraphs on the basis of our reading and other research activities. An interesting example of this process can be found in the second part of the posthumously published text by Maurice Merleau-Ponty, The Visible and the Invisible. It gives us insights into how a great phenomenologist prepared for his writing.

By way of example, I might attempt such linguistic transformation of the themes of parental expectations and hopes identified in the above section (6.1.2).

We can say that to be a parent is to have expectations and hope for a child. But "hope" is only a word, and a word soon becomes overworked, worn out, and forgetful of its original relation to the primordial. So we must examine how the living with children is ex- 
perienced such that we may call it "hope," having hope for children. To hope, to have hope for a child, is much more a way of being present to the child than a kind of doing. Hope for the parent is a mode of being. We may say "I hope that ..." with reference to particular expectations and desires: "I hope that my child will do well in school" "I hope that he can do his homework." These are the hopes which come and go with the passing of time. But children make it possible for men or women to transcend themselves and to say "I hope ... I live with hope; I live life in such a modality that I experience children as hope." This experience of hope distinguishes a pedagogic life from a non-pedagogic one. It also makes clear that we can only hope for children we truly love, not in a romantic sense, but in the sense of pedagogic love. What hope gives us is the simple avouchment, "I will not give up on you. I know you can make a life for yourself." Thus hope refers to that which gives us patience, tolerance, and belief in the possibilities of our children. Hope is our experience of the child's possibilities. It is our experience of confidence that a child will show us how a life is to be lived, no matter how many disappointments we may have felt tested us. Is this not the experience of parenting as bearing? Thus hope gives us pedagogy itself. Or is it pedagogy which grants us hope? Like all great values their ontological roots seem to merge.

\subsection{Gleaning Thematic Descriptions From Artistic Sources}

For the artist, as well as for the phenomenologist, the source of all work is the experiential lifeworld of human beings. Just as the poet or the novelist attempts to grasp the essence of some experience in literary form, so the phenomenologist attempts to grasp the essence of some experience in a phenomenological description. A genuine artistic expression is not just representational or imitational of some event in the world. Rather, it transcends the experiential world in an act of reflective existence. An artistic text differs from the text of everyday talking and acting in that it is always arrived at in a reflective mood. In other words, the artist recreates experiences by transcending them.

These are some of the themes that may belong to the experience of mothering as gleaned from Phyllis Chesler's quote (see p. 57, section 4.5):

1. The transformation from womanhood to motherhood is as dramatic as birth itself. ("when you gave birth to me")

2. The birthday of the young child is experienced as the birthday of this transformation to motherhood. ("your age exactly")

3. Becoming a mother puts a woman in touch with something primordial. ("an ancient well")

4. The new child teaches the mother a more depthful understanding of life. ("you deepen me")

5. The mother experiences the little child as a being who seems to have a mission or purpose of its own. ("little astronaut") 
6. Having given birth to a child is sometimes experienced as a longing for original oneness, a torn intimacy. ("no longer beneath my heart")

7. Motherhood is experienced as if on new ground, connected to a newly born. ("married to a child")

8. Yet, paradoxically, the child is also always experienced as Other. ("your utter separate reality")

9. To give birth to a child and to motherhood is experienced as a miracle. ("alchemy")

\section{Determining Essential Themes}

In setting ourselves the aim of attempting a more full-fledged phenomenological description, we need to determine the themes around which the phenomenological description will be woven. With respect to the illustrative example of the topic of parenting, these themes could be included: (1) the way in which a child enters the life of a woman and a man, (2) the bearing and providing a space for children in one's life, (3) the living with children as a living with hope, (4) the being an example for one's child as a way of learning to orient oneself to the question of how a life is to be lived.

I have been impressed with the way that collaborative or seminar discussions on the themes and thematic descriptions of phenomena researched by different students are helpful in generating deeper insights and understandings. For example, one student researching the phenomenon "fear of water" will read a (second, third, or fourth) draft of his paper. And on the basis of this description other students share in what way the description does or does not resonate with their own experiences. Thus, themes are dropped, added or reformulated. Each student paper usually benefits in various draft stages from three or four of such collaborative seminar reflections. Sometimes such dialogic reflections on a certain phenomenon can be built right into the phenomenological interview process.

We recall that initially the focus is on gaining as much as possible personal, lived-experience descriptions. During follow-up interviews, the first concern is to fill out these experiential descriptions with further examples where needed. Then there is the stage when the transcript themes that have been identified by the researcher may be reflected on in more dialogic conversations where both the researcher and the interviewee collaborate in the attempt to interpret the significance of the preliminary themes in the light of the original phenomenological question. That is, the researcher appeals to the conversant to enter in dialogic reflection on the question, "Is this what the experience is really like?" And thus, the inter-view turns into an interpretive conversation wherein both partners selfreflectively orient themselves to the inter-personal or collective ground that brings the significance of the phenomenological question into view. For example, a student who researches the phenomenon of "birthing pain" will go back several times to the women with whom she conducts hermeneutic conversations about the experi- 
ence. The women then read her next draft description of the phenomenological themes as a starting point for further sharing about the nature of the lived experience of birthing pain, and so forth.

\section{Phenomenological Writing}

\section{Attending to the Speaking of Language}

The phenomenological method consists of the ability, or rather the art, to be sensitive-sensitive to the subtle undertones of language, to the way language speaks when it allows the things themselves to speak. This means that an authentic speaker must be a true listener, able to attune to the deep tonalities of language that normally fall out of our accustomed range of hearing, able to listen to the way the things of the world speak to us. The world is no conglomeration of mere objects to be described in the language of physical science, says Van den Berg. The world is our home, our habitat, the materialization of our subjectivity. Whoever wants to become acquainted with the world of mothers, fathers, children, and teachers should listen to the language spoken by the things in their lifeworlds, to what things mean in this world.

\section{Varying the Examples}

The Dutch phenomenologist Buytendijk once termed phenomenology "the science of examples." This is a way of making reference to the iconic quality of phenomenological knowledge. A phenomenological study does not describe the nature of a phenomenon in the same sense that, for instance, an ethnographer describes a certain culture. When an ethnographer describes the culture of a teencentre or a day-care environment, then the description is expected to contain a certain reality validity for the way this particular youth culture or that particular day-care setting is experienced by these particular young people or children. In contrast, phenomenological research as it has been approached in this text aims at elucidating those phenomenologically structural features of a phenomenon that helps to make visible, as it were, that which constitutes the nature or essence of the phenomenon. In other words, every phenomenological description is in a sense only an example, an icon that points at the "thing" which we attempt to describe. A phenomenological description describes the original of which the description is only an example. To say it differently, a phenomenological description is an example composed of examples.

If the description is phenomenologically powerful, then it acquires a certain transparency, so to speak; then it permits us to "see" the deeper significance, or meaning-structures, of the lived experience it describes. How is such transparency achieved? It is a function of the appropriateness of the themes that we have identified as well as a function of the thoughtfulness that we have managed to muster in creating exemplary descriptions (examples); such as by being sensi- 
tive to the evocative "tone" of language in which the descriptions are captured. A description is a fine one if it reawakens our basic experience of the phenomenon it describes but now in such a manner that we experience the more foundational grounds of the experience.

Varying the examples is the way in which we address the phenomenological themes of a phenomenon so that the "invariant" aspect(s) of the phenomenon itself comes into view. Sometimes this is done by trying to show how, for example, pedagogic hope differs from other kinds of "hope." In this case we may vary the example by attending to the kind of meaning of "hope" that is implied in the language of teaching. In doing so, we may gain a momentary view of the "real" meaning of the experience of pedagogic hope.

Let us focus for a moment on the modern "behavioral objectives" or "management by objectives" talk in terms of which educational theorists and administrators try to define teaching competence.

What are we to make of the language of teaching that is thus made available to teachers? Herein lies the irony of a profound contradiction: the language by way of which teachers are encouraged to interpret themselves and reflect on their living with children is thoroughly imbued with hope, and yet it is almost exclusively a language of doing-it lacks being. We do not know how to talk of our being with children as a being present with hope for these children. The language of objectives, aims, teacher expectations, intended learning outcomes, goals, or ends in view is a language of hope out of which hope itself has been systematically purged. The language of aims and objectives, therefore, is a language of hopeless hope. It is an impatient language that neither bears nor truly awakens. How does "having measurable objectives" differ from "having hope"? Teacher expectations and anticipations associated with certain aims and objectives differ from having hope for our children, in that expectations and anticipations easily degenerate into desires, wants, certainties, predictions. This also means that as teachers we close ourselves off from possibilities that lie outside the direct or indirect field of vision of the expectations. To hope is to believe in possibilities. Therefore hope strengthens and builds. On the other hand, the phenomenology of specific educational objectives or broad goals is to be involved with the future of the children we teach in such a way that we always see past the present and the present as past. And inherent in such living with children is the danger of always treating the present as burden, as something that must be overcome. There is little dwelling in such living.

The point is not that the curricular language of educational aims, objectives, or instructional intentions is wrong. Seen in proper perspective this language is probably largely an administrative convenience. Teachers have always planned what should go on in a particular course, class, or lesson. The problem is that in an age when the administrative and technological have penetrated and imbued 
themselves into the very blood of our lifeworld, teachers and even parents seem to have forgotten a certain kind of understanding: what it means to bear children, to hope for children entrusted to their care. Recalling what thus seems to be forgotten is a kind of recollecting of what belongs to the being of parenting and of what belongs to the being of teaching as in loco parentis. The nihilistic forgetfulness of the essence of our being as teachers curiously turns loose a certain self-destructiveness. This is evident in the problem lately referred to as teacher burn-out. Teacher burn-out is the modern case of the enduring problem of nihilism: the higher values are losing their value. The ends are lacking, said Nietzsche, there is no answer to this question: "What's the use?" And, actually the nihilistic "what's the use" is less a question than a sigh, a shrugging off of any suggestion that there might be cause for hope. Teacher burn-out is not necessarily a symptom of excessive output of effort, of being overworked. It is the condition when as teachers we no longer know why we are doing what we are doing. Teacher burn-out is hopeless in that nobody can make us believe there is an answer to the sigh, "What's the use?" The only way teacher burn-out can be overcome is by recapturing in ourselves the knowledge that life is bearable-not in the sense that we can bear it, as we bear a burden which weighs us down, but in the sense that we know that life is there to bear us-as in the living with hope. We can do this, once again, by seeing the child as child, by giving birth and bearing to children, rather than aborting the child in the middle of the abstracted rhetoric of our theorizing.

\section{Writing}

Although there is no compelling reason for structuring a phenomenological description in any one particular way, it may be helpful to organize one's writing in a manner that is related to the essential structure of the phenomenon itself. Here follow some alternative ways of structuring one's descriptions:

Thematically. First, the phenomenon of parenting could be described by organizing one's writing around the themes of bearing children, preparing the child's world as a place to be and to become, living with children as living with hope, and exercising parental responsibility as a way of being responsive to that which authorizes us to be parents in the first place.

Analytically. Alternatively, one may conduct one's writing analytically in an ever deepening search for ground. Such an approach might take the shape of following some of the procedural activities outlined above. For example, one may start with some situation or event taken from everyday life in order to show how the experience of parenting as a phenomenon is ill-understood, how taken-forgranted or generally accepted conceptualizations gloss rather than reveal a more thoughtful understanding of the nature of parenting. Next, one could reflectively show how certain themes emerge from 
considering etymological and idiomatic sources, from examining ex periential descriptions, literary and phenomenological material and so forth.

Exemplicatively. Another way of proceeding in phenomenologica writing is to begin the description by rendering visible the essentia nature of the phenomenon and then fill out the initial description by systematically varying the examples. For example, after explicating the essential structure of the phenomenon of parenting, one woulc proceed by showing how this description is illuminative for and illu. minated by considering various modalities of parenting: being ar adoptive parent, being a stepmother or stepfather, parenting disa. bled children, being a young parent or an older parent, being a single or divorced parent, being a parent of a lost child, and so forth. Eack. case could enlighten some essential aspects of the nature of parenting.

Existentially. A fourth way of proceeding in phenomenological writing is to weave one's phenomenological description against the existential themes of temporality (lived time), spatiality (lived space), corporeality (lived body), communality (lived relationship to others), etc. In other words, one could structure the phenomenological description around the question of how parents experience time differently from non-parents, how parents experience space or place differently from non-parents, and so on.

Exegetically. Finally, a phenomenological description could be organized by engaging one's writing in a dialogical or exegetical fashion with the thinking of some other phenomenological author. This approach is often taken when the classic themes of phenomenology are being discussed. For example, Zaner's Phenomenology of Embodiment is organized around the writings on the phenomenology of the body by Sartre, Marcel, and Merleau-Ponty. In the case of the phenomenon of "fathering" ("mothering" or "parenting"), one could begin by addressing the works of Gabriel Marcel and M. J. Langeveld who see the essence of fathering to consist in "the vow," and in the active declaration of responsibility.

These five suggestions for organizing one's phenomenological description (thematically, analytically, exemplificatively, existentially, or exegetically) are neither exhaustive nor mutually exclusive. A combination of the above approaches could be used. It should be clear that the approach one takes in the phenomenological description should partly be decided in terms of the nature of the phenomenon being addressed.

\section{Rewriting}

In spite of the seemingly instrumental character of this procedural approach, the methodology of phenomenology is more a carefully cultivated thoughtfulness than a technique. Phenomenology has been called a method without techniques. The "procedures" of this 
methodology have been recognized as a project of various kinds of questioning, oriented to allow a rigorous interrogation of the phenomenon as identified at first and then cast in the formulation of a question. The methodology of phenomenology requires a dialectical going back and forth among these various levels of questioning.

Language is a central concern in phenomenological research because responsive-reflective writing is the very activity of doing phenomenology. Writing and rewriting is the thing. Phenomenologists have commented on the reflexive character of writing. Writing (like "se decider," the French word for deciding; i.e., making up one's mind) is a deeply reflexive activity that involves the totality of our physical and mental being. To write means to write myself, not in a narcissistic but in a deep, collective sense. To write phenomenologically is the untiring effort to author a sensitive grasp of being itself-of that which authors us, what makes it possible for us to be and speak as parents and teachers, etc., in the first place.

As an aspect of the methodology of phenomenology, the experience of recalling has been described as a form of recollecting, a gathering of the kinds of understandings that belong to being. This is the search for the ontological difference; it is a search for the understanding of the logos that lets us be mothers and fathers.

And herein lies a responsibility for phenomenology. This recollective thinking needs to be brought to speech, much like what happens in the poetizing writing of the poet who gives form to an authentic speaking. Rilke called this thinking a kind of blood remembering. An appropriate term, since for us parents and teachers the blood remembering implies a recognition of the memory that children are indeed of our blood: a recognition which, like a vow, becomes full of an unconditional quality, a recognition which is a heeding of the sign of a presence. And we experience the incarnation of this presence in the "us" from which my hope in this child derives its meaning-that is to say, a togetherness of which I proclaim the indestructibility.

\section{Notes}

1. Ed. CI 652. See University of Alberta calendar.

2. See Monograph "Life World Studies." Department of Secondary Education Publication, The University of Alberta. Edmonton, Canada.

3. See Barritt, Beekman, Bleeker, and Mulderij in this issue for an excellent description of this activity. Over the past years I have been stimulated by many friendly and provocative discussions with Ton Beekman, whose thoughtfulness and perceptiveness I appreciate and admire.

\section{References}

Chesler, P. (1979). With child: A diary of motherhood. New York: Thomas Y. Crowell.

Gadamer, H. G. (1975). Truth and method. New York: The Seabury Press. 
Gusdorf, G. (1965). Speaking (La Parole). Evanston: Northwestern University Press.

Heidegger, M. (1962). Being and time. New York: Harper \& Row.

Heidegger, M. (1971). Poetry, language, thought. New York: Harper \& Row.

Husserl, E. (1970). The crisis of European sciences and transcendental phenomenology. Evanston: Northwestern University Press.

Langeveld, M. J. (1971). Erziehungskunde und Wirklichkeit. Braunschweig: Georg Westermann Verlag.

Marcel, G. (1978). Homo viator. Gloucester, Mass: Peter Smith.

Merleau-Ponty, M. (1962). Phenomenology of perception. London: Routledge and Kegan Paul.

Merleau-Ponty, M. (1968). The visible and the invisible. Evanston: Northwestern University Press.

Merleau-Ponty, M. (1973). The prose of the world. Evanston: Northwestern University Press.

Mood, J. J. L. (1975). Rilke on love and other difficulties. New York: W. W. Norton.

Nietzsche, F. (1962). Philosophy in the tragic age of the Greeks. Chicago: Henry Regnery Co.

Rilke, R. M. (1977). Possibility of being: A selection of poems. New York: New Directions.

Schaffer, R. (1977). Mothering. Cambridge, Mass.: Harvard University Press.

Van den Berg, J. H. (1974). A different existence. Pittsburgh: Duquesne University Press.

Woolf, V. (1932). The common reader, I. Honolulu: HI: Hogarth Press. 